\title{
$\Delta=$
}

\section{ANÁLISE DE POSSIBILIDADES DIDÁTICAS NA CONSTITUIÇÃO DA PRÁXIS PEDAGÓGICA DO FORMADOR DE PROFESSORES}

\author{
ANALYSIS OF POSSIBILITIES FOR TEACHING IN CONSTITUTION PRAXIS \\ EDUCATIONAL TEACHERS TRAINER
}

Walêska Dayse Dias de Sousa ${ }^{1}$

\begin{abstract}
RESUMO
Este artigo tem como objetivo analisar possibilidades didáticas que contribuam com a constituição da práxis pedagógica do formador de professores. É parte de pesquisa de doutorado concluída em 2016 que realizou intervenção didático-formativa com formadores de professores que atuam nos cursos de licenciatura da UFTM. Os procedimentos teórico-metodológicos que orientaram a pesquisa foram constituídos em três etapas: diagnóstico, intervenção e análise de dados, com a realização de entrevistas, observação de aulas e encontro de estudos. O referencial teórico-metodológico utilizado foi a teoria histórico-cultural, que valoriza o bom ensino entendendo que a sua organização adequada e consciente contribui para adiantar e guiar o desenvolvimento dos sujeitos. Entre os resultados alcançados observou-se que o formador de professores constitui sua práxis pedagógica quando tem domínio teórico de conceitos que fundamentam sua prática, possibilitando que ele faça escolhas didáticas conscientes e intencionais, contribuindo, assim para o seu desenvolvimento profissional.
\end{abstract}

Palavras-chave: Práxis pedagógica. Teoria histórico-cultural. Didática desenvolvimental. Docência universitária.

\begin{abstract}
This article aims to analyze educational opportunities that contribute to the formation of the pedagogical praxis of a teacher trainer. It is part of doctoral research completed in 2016 that held didactic-training intervention with teacher trainers who work in undergraduate courses UFTM. The theoretical and methodological procedures that guided the research were made in three stages: diagnosis, intervention and analysis of data, conducting interviews, classroom observation and study meeting. The theoretical framework used was the historical-cultural theory that values good teaching understanding that adequate and conscious organization helps to advance and guide the development of the subjects. Among the results achieved it was observed that the teacher educator is their pedagogical praxis when it has theoretical domain concepts that underlie their practice, enabling him to make educational choices conscious and intentional, thus contributing to their professional development.
\end{abstract}

Keywords: Pedagogical praxis. Historical-cultural theory. Didactic developmental. University teaching.

\footnotetext{
${ }^{1}$ Universidade Federal de Uberlândia. Programa de Pós-Graduação em Educação (FACED). Apoio CAPES / CNPq. E-mail: waleskadayse@yahoo.com.br
} 


\section{Introdução}

Este artigo tem como objetivo analisar possibilidades didáticas que contribuam com a constituição da práxis pedagógica do formador de professores. É parte de pesquisa de doutorado concluída em 2016 que realizou intervenção didático-formativa com formadores de professores que atuam nos cursos de licenciatura da Universidade Federal do Triângulo Mineiro - UFTM. Integra os propósitos do Grupo de Estudos e Pesquisa em Didática e Profissionalização Docente - GEPEDI da Universidade Federal de Uberlândia - UFU. Com base nos estudos realizados pelo grupo, observa-se que a produção de didática no país tem-se destacado, em grande parte, por estudos teóricos, com poucas iniciativas voltadas para compreender modos e condições de organização e realização de práticas pedagógicas. Assim, atenta ao estado atual da pesquisa em didática no país e procurando responder a lacuna existente relacionada a proposições investigativas de cunho teórico-prático, organizou-se a investigação. Ela teve como problemática geral compreender como um processo formativo pode contribuir para que o formador de professores escolha, conscientemente, do ponto de vista teórico e prático, portanto, enquanto práxis, opções didáticas adequadas ao ensino que promovam aprendizagem e, por conseguinte, potencializem o seu desenvolvimento e dos seus estudantes.

$\mathrm{O}$ estudo foi organizado em três sessões. Na primeira é apresentado o referencial teórico-metodológico que orientou a investigação, na segunda é apresentada, brevemente, a metodologia utilizada, na terceira são apresentados os resultados e discussões e para concluir as considerações finais.

\section{Referencial teórico}

O referencial teórico-metodológico utilizado no decurso de toda a investigação foi a teoria histórico-cultural. Esta teoria, de fundamentação filosófica marxista, tem como principal representante o psicólogo russo Vigotski (2007), que compreende a constituição humana pela sua relação ativa com a cultura. A interiorização do mundo social se produz com a atividade do sujeito, transformando o externo em interno, o objetivo em subjetivo, não de forma linear direta, mas por meio de uma apropriação criadora que transforma o sujeito e também o mundo. Em função do processo de constituição humana ser mediado simbolicamente pela cultura, o ensino assume grande importância na teoria histórico-cultural. 
Vigotski (2007) valoriza o ensino considerando-o fundamental quando adianta o desenvolvimento e o guia. Para que isto ocorra deve ser organizado de forma adequada e intencional, na perspectiva do ensino desenvolvimental.

O processo formativo realizado com os formadores de professores foi chamado de intervenção didático-formativa. Pode-se defini-lo como um processo investigativo-formativo coletivo realizado no âmbito do ensino superior, incluindo ações de instrumentalização/formação, planejamento de atividades de ensino e estudo, observação de aulas, análise e avaliação numa perspectiva de unidade dialética com o objetivo de contribuir com o desenvolvimento integral de professores e alunos, tendo em vista uma práxis revolucionária.

Tal processo atendeu às peculiaridades da pesquisa, voltadas para preocupações teórico-práticas. Na tradição da teoria histórico-cultural, usualmente, se utilizava o experimento formativo, próprio da área de psicologia e assim era necessário produzir uma metodologia própria que estivesse fundamentada nos conceitos de dialética e práxis enquanto referências teórico-metodológicas da investigação. No que diz respeito à dialética como lógica, compreende-se que ela consegue relacionar a objetividade do conteúdo dos conceitos e teorias científicas com a sua historicidade, movimento de transformação permanente e instabilidade. Constitui-se em base do processo de apreensão de um objeto em sua essência:

[...] para conhecer realmente um objeto, é preciso abrangê-lo, estudar todos os seus aspectos, todas as relações e mediações. Nunca conseguiremos isto plenamente, mas a exigência de multilateralidade nos previnirá contra erros e necrose. Isto, em primeiro lugar. Em segundo, a lógica dialética exige que se tome o objeto em seu desenvolvimento, automovimento (como Hegel às vezes dizia), em mudança... Em terceiro lugar, toda a prática humana deve incorporarse à plena definição do objeto quer como critério da verdade, quer como determinante prático da relação entre o objeto e aquilo de que o homem necessita. Em quarto lugar, a lógica dialética ensina que não há verdade abstrata, que a verdade é sempre concreta (KOPNIM, 1978, p. 82).

No que diz respeito ao conceito de práxis, percebe-se que ele tem uso recorrente na literatura que trata do tema da formação de professores numa perspectiva marxista (FREITAS, 2005; GONÇALVES, 2009; LIMA, 2009; MONTEIRO, 2013; NORONHA, 2010). Grande parte dessas publicações discute o conceito estabelecendo relação ao trabalho que é desenvolvido pelo professor, seja produzindo críticas às apropriações que são 
objetivadas, seja indicando diagnósticos dessa atividade que as aproximam (ou não) do conceito. O sentido de práxis mais utilizado nessas produções é da relação entre teoria e prática que se objetiva (ou não) na prática do professor.

Tal recorrência do uso do termo poderia supor, aparentemente, que se trata de uma apropriação consistente entre os professores, incorporada a um discurso pedagógico e a uma prática docente, como se todos os professores exercessem a práxis, do ponto de vista marxiano, em suas rotinas profissionais. Ocorre que esse não é encaminhamento mais comum verificado nas diferentes publicações. Embora o uso do termo seja recorrente, nelas se destacam “denúncias" de que a verdadeira práxis pedagógica para muitos professores ainda é um caminho a ser trilhado.

Tal conclusão não surpreende, considerando que os professores reais estão imersos em um contexto alienante, em que na maioria das vezes não é possível se reconhecer em seu trabalho docente. A práxis verdadeira tem como fundamento a teoria. Ela potencializa a atividade transformadora, desde que os homens concretos tenham consciência de si e façam a si mesmos uma crítica radical, o que nem sempre se verifica no trabalho dos professores.

A crítica radical é aquela que ataca o problema pela raiz e o problema é o próprio homem, sua produção. Sendo assim, a crítica radical para o professor é pensar como ele tem se produzido professor, tendo em vista as condições objetivas de que dispõe, os referenciais que tem utilizado e como esses elementos tem se organizado para satisfazer suas necessidades. De acordo com Sánchez Vásquez (2011, p. 119) "a passagem da crítica radical do plano teórico ao prático é justamente a revolução". E ainda: "A práxis é, portanto, a revolução, ou crítica radical que, correspondendo às necessidades radicais, humanas, passa do plano teórico ao prático".

Tomando como base os construtos da teoria histórico-cultural e os conceitos de dialética, numa perspectiva materialista e práxis, foram analisadas algumas possibilidades didáticas que contribuem para que o formador de professores se desenvolva na profissão, tendo por um lado, fundamento teórico para embasar sua organização do ensino, e por outro, consciência e intencionalidade na materialização do seu fazer docente.

\section{Metodologia}

A pesquisa foi desenvolvida em três etapas. Na primeira, foi realizado diagnóstico do ensino com cinco formadores de professores que atuam nos cursos de licenciatura da UFTM 
em disciplinas voltadas para o ensino de cada área específica: Física, Geografia, História, Letras e Química. Todos os professores do grupo têm atuação docente superior a cinco anos, sendo quatro doutores e um doutorando em suas respectivas áreas, idade média de 35 anos, quatro do gênero feminino e um do gênero masculino. Foram selecionados por representar as três grandes áreas de conhecimento dos cursos de licenciatura existentes na instituição: áreas de Ciências Humanas e Sociais, Ciências Exatas e Letras. Nesta etapa, com duração de um semestre, foram realizadas entrevistas gravadas e observação de aulas dos cinco professores, registradas por escrito por meio de um roteiro de observação.

$\mathrm{Na}$ segunda etapa da pesquisa foi realizada intervenção didático-formativa com uma das formadoras de professores que integraram a fase de diagnóstico, da área de ensino de Geografia. A intervenção não foi realizada com o grupo dos cinco formadores iniciais em função das condições de trabalho dos professores do ensino superior, marcada pela grande demanda de atribuições. Assim, eles reconhecem a importância e necessidade de seu desenvolvimento permanente na profissão docente, mas nem sempre conseguem articular condições adequadas para a sua realização.

A etapa de intervenção, com duração de um ano, foi realizada com as ações de instrumentalização/formação, planejamento de aulas, realização de aulas e avaliação do processo. Os procedimentos utilizados nesta etapa foram: encontros de estudos, entrevistas e observação de aulas. Foram produzidos registros escritos da etapa de intervenção didáticoformativa a partir dos instrumentos que foram produzidos para este fim e ela contou com a participação de um aluno de iniciação científica que apoiou a pesquisa realizando registros dos encontros de estudo.

$\mathrm{Na}$ terceira etapa foi realizada análise dos dados. Compreendendo que "fazer ciência é trabalhar simultaneamente com teoria, método e técnicas" (MINAYO, 2011, p. 622), para a análise dos dados produzidos na etapa de intervenção didático-formativa, após intensa familiarização, foram definidas três unidades de análise, consideradas constituintes da práxis pedagógica do formador de professores: apropriação teórico-prática: da necessidade formativa a consciência do conceito; o movimento imitação - criação: em busca de um processo emancipador e docência mediada pelos conceitos na elaboração de instrumentos. A análise das possibilidades didáticas que colaboram para a constituição da práxis pedagógica do formador de professores, objeto do presente artigo, integra a análise dos dados da pesquisa.

A instituição onde a pesquisa foi realizada, ou seja, a UFTM é uma instituição jovem, que enquanto universidade possui apenas dez anos de existência. Foi aprovada por meio da lei 
11.152 de 29/07/2005, publicada no Diário Oficial da União de 01/08/2005. Antes, durante 50 anos, funcionou como faculdade isolada, com três cursos superiores na área de saúde: medicina, biomedicina e enfermagem. Posteriormente foram criados outros e atualmente já são ofertados 25 cursos de graduação. Os cursos de licenciatura da instituição foram criados em 2009 por meio do seu projeto de expansão e foram viabilizados pelos recursos do Programa de Apoio a Planos de Reestruturação e Expansão das Universidades Federais Reuni. São cursos noturnos criados para racionalizar a ocupação dos espaços ociosos da instituição no período da noite, voltados para formar professores para a educação básica da região do seu entorno, constituída, sobretudo, dos estados de Minas Gerais e São Paulo.

\section{Discussões e resultados}

Para escolher conscientemente à forma de conduzir o processo ensino-aprendizagem, articulando-o a um princípio teórico e dessa forma constituir o trabalho docente enquanto práxis, é necessário questionar a maneira tradicional que a escola, nos diferentes níveis, organiza o processo didático. Muitas vezes, os próprios professores qualificam este processo, em geral, como pouco produtivo, mecânico, repetitivo, no qual o aluno tende a realizar pouco esforço mental (SILVESTRE ORAMAS, 2003). Tradicionalmente se apresentam conceitos que são memorizados pelos alunos e na sequência são aplicados exercícios para sua fixação. Como conseqüência, não há aprendizagens duradouras, o que foi memorizado logo é esquecido e o aluno pouco participa.

\footnotetext{
Não se exige uma reflexão profunda, a determinação do essencial, o estabelecimento de nexos, a argumentação, o vínculo do que se aprende com a prática social, a valorização da utilidade, a autovalorização do que se faz, da sua conduta e de seus companheiros. Essa pobreza gera um estudante com muito pouco protagonismo no processo da aula, pouco independente, que se aborrece e, muitas vezes, deseja que o turno das aulas termine logo (SILVESTRE ORAMAS, 2003, p. 21).
}

Diante disso, urge a necessidade de desenvolver uma didática que se ocupe da organização adequada da atividade de ensino-aprendizagem, de forma que contribua para o desenvolvimento, ou seja, para a criação de formações novas; mudanças qualitativas na vida psíquica do homem (Talízina, 2000); uma didática que tenha no ensino intencional seu objeto, 
na aprendizagem sua condição e no desenvolvimento da personalidade integral do estudante seu objetivo (PUENTES e LONGAREZI, 2012).

A formadora que participou da intervenção didático-formativa, que se convencionou chamar pelo nome fictício de Santana, procurou organizar suas aulas junto aos estudantes partindo da preocupação de perceber como eles estavam se aproximando dos estudos propostos. Para isso foi elaborado questionário diagnóstico logo no início de uma disciplina ministrada por ela, com estudantes de licenciatura. Tal questionário foi elaborado durante a ação de planejamento, no decorrer da intervenção didático-formativa. Com a análise dos questionários a formadora teve a oportunidade de comentar com os estudantes: "percebi na leitura do questionário diagnóstico de vocês, respostas muito gerais, amplas "... (SANTANA, registro de observação de aulas), o que pode ser analisado como momento decorrente de uma etapa de desenvolvimento dos estudantes ainda muito referendada pelos conhecimentos espontâneos, ou seja, produzidos de forma cotidiana, relacionados à docência.

Com o questionário, teve-se como finalidade perceber que conhecimentos os estudantes já detinham em relação à profissão docente, especialmente no que diz respeito ao planejamento de ensino, além de suas compreensões iniciais acerca de conceitos da teoria histórico-cultural. Com a delimitação das questões diagnósticas, os estudantes também puderam observar alguns elementos que seriam importantes na condução da disciplina, ou seja, as questões revelaram o conteúdo a ser desenvolvido. Desde o início os estudantes tiveram uma participação ativa no processo, pois foram envolvidos de tal forma que precisaram encontrar soluções para os problemas apresentados.

Embora importante, Vigotski (2007) explica que apenas conhecer o nível de desenvolvimento atual do estudante é insuficiente para orientar, de forma intencional, a atividade de ensino-aprendizagem. Portanto ele inicia uma série de experimentações e explica um novo procedimento metodológico:

Suponhamos que determinamos a idade mental de duas crianças e que esta resultou ser de oito anos. Se não nos determos nisso e tratamos de explicar como eles resolvem testes previstos para idades seguintes, testes que não estão em condições de resolver por si mesmos, se ajudamos através de demonstrações, perguntas sugeridas, ensinandoos como começar sua resolução, poderemos observar que um deles, com ajuda, com colaboração, com indicações, será capaz de resolver testes correspondentes a idade de doze anos, e o outro, testes correspondentes a idade de nove. Esta diferença entre a idade mental, o nível atual de desenvolvimento, determinado por meio da resolução independente de tarefas e o nível alcançado pela criança quando 
resolve tarefas não de forma autônoma, senão assistida, determina a zona de desenvolvimento próximo. (VIGOTSKI, 2007, p. 353).

Mais adiante ele complementa: "a investigação mostra que a zona de desenvolvimento próximo tem uma importância mais direta para a dinâmica do desenvolvimento intelectual e o êxito da instrução que o nível atual de seu desenvolvimento". (VIGOTSKI, 2007, p. 354).

Dessa forma, organizar diagnósticos para identificar que conhecimentos os estudantes já construíram e utilizam com independência deve ser complementado com diagnósticos que indiquem os conhecimentos que eles ainda precisam alcançar; aqueles em que se observa a necessidade de colaboração. Esta deve ser uma tarefa a ser desempenhada pelo professor. Procedimento para que ele, a partir daí, possa planejar seu trabalho didático com a compreensão do potencial que o estudante possui para avançar no processo de aprendizagem e desenvolvimento.

Santana se apropriou deste princípio e o utilizou ao longo da intervenção didático formativa, pois buscou formas de perceber como os estudantes foram se aproximando dos estudos que propôs, seja com o uso de questionários diagnósticos, seja com perguntas que interrogassem as práticas deles no campo de estágio. Do mesmo modo, a intervenção também considerou esta orientação, pois se organizou a partir de necessidades dos formadores que foram apresentadas em suas expressões escritas e orais, de variadas formas.

A formadora, ao utilizar o procedimento em que formulava questões aos estudantes para que eles se referissem às experiências docentes do estágio, sobretudo relacionadas às formas de analisar os conhecimentos atuais dos alunos do campo de estágio assim se expressou em uma situação: “Como foi o retorno do questionário para levantar os conceitos espontâneos no campo de estágio do asilo? (SANTANA, registro de observação de aulas)". Os estudantes responderam: "Para eles educação ambiental é zelar do meio ambiente, é plantar no quintal, não comprar nada (ESTUDANTES, registro de observação de aulas)”".

$\mathrm{Na}$ situação descrita, Santana não questionou aos estudantes sua compreensão acerca da definição de "conceito espontâneo", o que poderia fazer com que eles recorressem à memorização da definição que não seria, necessariamente, uma indicação de aprendizagem. A formadora foi além pedindo aos estudantes uma aplicação do conceito a uma situação real do ensino. A resposta dos estudantes se constituiu assim, numa solução ao problema apresentado e numa indicação para a formadora do processo de aprendizagem. Pode-se concluir, portanto, que a opção didática de Santana esteve voltada para uma perspectiva desenvolvimental. 
Ao longo dos encontros de estudo a organização das propostas também foi analisada. Assim, a ação de instrumentalização foi organizada didaticamente sob a base dos seguintes princípios: partir de necessidades formativas dos sujeitos da pesquisa; considerar o diagnóstico do nível de desenvolvimento dos formadores no que diz respeito ao ensino; propor problemas aos formadores que os levassem a analisar os nexos dos conceitos estudados e organizar novos planejamentos para suas próprias aulas com base nos conceitos. Tais princípios foram desenvolvidos a partir de orientações didático-formativas como as elencadas a seguir:

Vou apresentar a vocês a sistematização do diagnóstico do ensino realizado anteriormente. Que avaliação vocês fazem desse diagnóstico?

Faça um desenho ou esquema que represente o ensino superior no contexto atual sob o título: Fundamentos teórico-práticos da docência universitária no contexto atual.

Por que o professor precisa discutir as relações entre aprendizagem e desenvolvimento?

A partir das cenas selecionadas do filme: A Maçã, vamos discutir o conceito de humanização.

Com base no texto de Piaget e a teoria histórico-cultural vamos estabelecer as diferenças entre elas.

A partir da definição: formação de conceitos, que elementos essenciais e suficientes colaboram em sua definição? Vamos discutir a rede conceitual que se forma a partir do texto (registros da intervenção didático-formativa).

Nas proposições didáticas destaca-se o fato de que era necessário realizar leituras prévias para conseguir encaminhar as questões levantadas. Isto demonstra uma característica específica desta área de conhecimento: sua apreensão demanda o reconhecimento do estado atual da produção conceitual, para a partir daí serem realizadas análises e sínteses. As leituras prévias por parte dos formadores e depois por parte de Santana não foram uma negociação simples. Inúmeras vezes eles reconheciam não ter conseguido fazer a leitura indicada com antecedência e justificavam pela grande demanda de atribuições assumidas. Reproduziam um comportamento que muitas vezes é sentido entre os estudantes de graduação, mesmo eles reconhecendo que a leitura prévia é condição essencial para os estudos na área de ciências humanas e sociais, na qual a educação, a psicologia e a didática estão inseridas. 
As proposições didáticas que orientaram a intervenção quase sempre demandavam a realização de procedimentos mentais: análises, comparações, argumentações, descrições, representações, avaliações. O desenvolvimento dos procedimentos envolvia os formadores nos estudos, obrigando-os a atuar sobre os conteúdos teóricos, posicionar-se frente ao que eles apresentavam. $\mathrm{Na}$ ação de planejamento este processo exigia mais: além dos procedimentos mentais antes realizados, demandava uma prévia idealização de uma ação orientada a um fim. Com o desenvolvimento das aulas, era inevitável a avaliação de todo este percurso, para que ele fosse reformulado permanentemente. Santana indicou isso ao responder ao questionamento: "Você percebe contribuições desses estudos teóricos para organização da sua prática docente?" (registro de entrevista com a formadora). Santana respondeu:

Eu acho que percebo mesmo. Por exemplo, este semestre que você não está diretamente observando minhas aulas [...] eu optei sozinha por estudar alguns textos que estudamos juntas, estudar os conceitos da teoria, orientar um estágio inteirinho acreditando minimamente que estaria contribuindo com a formação dos alunos com subsídios teórico-metodológicos para a prática deles... (SANTANA, registro de entrevista).

A formadora revela a modificação da forma anterior da organização: "agora o que a gente planejou eu estou refazendo tudo" (SANTANA, registro de entrevista). Ela demonstra sua autonomia conquistada e sua compreensão de que a organização didática está sempre em movimento, com escolhas que devem estar articuladas a diferentes dimensões do processo educativo. A organização didática deve refletir um contexto de ensino determinado, em que sujeitos reais se movimentam, demandam, se apresentam em suas necessidades e peculiaridades. Por isso, a cada processo formativo o professor precisa reorganizar sua idealização prévia, considerando finalidades, conteúdos, condições objetivas de que dispõe e características que os estudantes reais lhe apresentam. A organização didática se relaciona a todos estes elementos.

A teoria da atividade de Leontiev (1978), compreende que o sujeito se produz humano quando idealiza e realiza uma ação intencional visando a um fim. Compreende-se que esta teoria tem potencial para colaborar com a organização do trabalho pedagógico, uma vez que reafirma princípio da teoria histórico-cultural: o de que só se aprende e se desenvolve em atividade. $\mathrm{O}$ homem é um sujeito ativo, que só consegue se constituir ao transformar o externo em interno, o objetivo em subjetivo por meio da sua atuação intencional. Na 
pedagogia tradicional, o aluno é apenas receptor de conhecimentos. Ele não atua sobre eles, não os produz; apenas os recebe e os guarda de forma passiva.

Uma prática pedagógica que considere princípios da teoria da atividade como um de seus fundamentos deve organizar procedimentos didáticos que dêem protagonismo aos alunos; que os instrumentalizem para agir enquanto apreendem os elementos essenciais de um determinado conceito; que possibilite aos alunos realizar operações mentais de comparação, análise, síntese, classificação.

Santana considerou a teoria da atividade na organização do seu trabalho didático. Como dito por ela, a teoria a ajudou a pensar melhor nesta organização, a elaborar seu planejamento de aulas com finalidades um pouco mais precisas. Afinal uma prática referendada por esta teoria necessita de uma estrutura intencional e clara, em que os elementos do sistema didático, ou seja, objetivos, conteúdos, metodologias e formas de avaliação estejam coerentemente articulados, significados e, portanto, passíveis de se traduzirem em sentidos pessoais para os alunos, mediante a busca de motivação a percorrer todo o processo. Isto porque a atividade, tal como teorizada por Leontiev não é um processo simples. Ao contrário, é complexo; possui uma estrutura e conforma um sistema de elementos interdependentes, assim como o processo de ensino-aprendizagem.

Numa situação junto aos estudantes, em que Santana discute o planejamento das aulas no campo de estágio ela pontua: "Ficar só na discussão pode não levar os alunos a realizar alguma atividade de estudo, nenhum processo analítico... Como esse ensino vai potencializar o desenvolvimento?" (SANTANA, registro de observação de aulas). A formadora chama a atenção para a necessidade dos estudantes planejarem situações em que seus alunos estejam atuantes sobre os conceitos de estudo, portanto, em atividade.

Outro dado analisado na pesquisa foi o relacionado à questão das orientações formuladas pelos professores aos estudantes para realizar atividades desenvolvidas no processo educativo. Com os estudos, Santana foi levada a pensar na qualidade destas orientações. Ela mesma indicou isso referindo-se à intervenção didático-formativa: " $E$ uma coisa que eu posso falar que vai ficar, que eles sabem onde eles vão chegar, se você deixar claro" (SANTANA, registro de entrevista).

A formadora considerou que a orientação para o estudo, tarefa que é desempenhada pelo professor e que nem sempre recebe importância, pode contribuir com a aprendizagem pretendida. Além disso, pode colaborar para que o estudante conquiste sua autonomia para os estudos, uma vez que ele pode perceber onde pode chegar com determinada tarefa. Uma base 
orientadora (GALPERIN, 1957) que inclua finalidades, a essência dos conceitos a ser apreendidos, o caminho por onde se pretende chegar para alcançar determinado objetivo são elementos que contribuem para a qualidade da organização didática, e portanto tem potencial para a aprendizagem dos sujeitos.

Assim, as orientações organizadas pelos professores no seu processo de organização didática merecem toda a atenção. Santana reconhece isso quando faz a crítica: "Ao propor elaborar uma ação é preciso cuidado para não virar um pinte o mapa (SANTANA, registro de observação de aulas)”. O exemplo que ela apresenta ilustra bem uma situação naturalizada em muitas práticas pedagógicas, em que os estudantes realizam ações, mas não entendem as justificativas para realizá-las. Copiam, pintam, mas não são levados a pensar nas finalidades educativas do seu ato, que passa a ser puramente mecânico, sem envolver atos de pensamento. Ao se posicionar quanto à questão junto aos estudantes, orientando-os para as aulas no campo de estágio a formadora conclui: "Se nos preparamos mostramos nossas intenções" (SANTANA, registro de observação de aulas).

\section{Considerações finais}

As análises empreendidas ao longo da investigação indicaram que os esforços dos formadores de professores no processo de organização didática podem contribuir na constituição de sua práxis pedagógica, desde que rompam com processos alienantes. Assim, tal organização deve ser o reflexo de um movimento de unidade entre teoria e prática; de consciência da necessidade formativa a materialização do fazer docente. A intuição deve ceder lugar à intenção, assim como a reprodução de modelos deve abrir espaço à criação do professor. Só dessa forma o formador de professores poderá trilhar seu caminho revolucionário: emancipando-se da naturalização de ações, da repetição de técnicas como se fossem neutras, de um espontaneismo que não o conduz ao desenvolvimento profissional.

A pesquisa demonstrou que isto é possível, desde que exista uma necessidade e uma atividade do formador para superar-se. A via do estudo é o caminho possível para o alcance deste objetivo, o que implica num investimento pessoal do formador para realizá-lo. O estudo deve estar fundado em questões que o mobilizem para encontrar soluções aos problemas do ensino apresentados, ressignificando a didática enquanto área de conhecimento fundamental para o trabalho do professor. 
Os dados registrados durante o processo da pesquisa constituem vasto material de análise, tendo em vista a extensão do processo interventivo que se materializou. Assim, eles poderão responder a inúmeras outras indagações que porventura vierem a ser formuladas durante os debates a serem promovidos com a socialização da investigação. Constituem referência que pode trazer grandes contribuições para a área de didática no país, sobretudo por seu caráter de articulação teórico-prático.

Assim, considera-se que os resultados ora divulgados constituem as primeiras formas de sistematização dos dados, podendo ser enriquecidas à medida que se aprofundarem os debates decorrentes. Que eles venham, para que dessa forma se beneficie a área e todos os sujeitos que, cotidianamente, materializam em suas práticas profissionais a busca permanente por uma práxis revolucionária e emancipatória.

\section{Referências}

FREITAS, M. A. S. F. Práxis pedagógica e professores intelectuais: refletindo as tensões e concepções da formação/prática docente. In: Práxis Educacional, Vitória da Conquista, n. 1, p. 135-150, 2005.

GALPERIN, P.Ya. Sobre la formación de las imágenes sensoriales y de los conceptos, 1969. En: Colección de materiales de conferencias sobre Psicologia. Facultad de Psicologia, Universidad Estatal de Moscú, 1957.

KOPNIM, P. V. A dialética como lógica e teoria do conhecimento. Rio de Janeiro: Civilização Brasileira, 1978.

LEONTIEV, A. Sobre o desenvolvimento histórico da consciência. In: LEONTIEV, A. $O$ desenvolvimento do psiquismo. Lisboa: Horizonte Universitário, 1978.

LIMA, M. S. L; GONÇALVES, H. H. A práxis docente no desempenho das atividades do professor formador. In: CONGRESSO NACIONAL DE EDUCAÇÃO, 9, 2009, Curitiba-PR, Pontifícia Universidade Católica do Paraná, Anais. Disponível em: http://www.pucpr.br/eventos/educere/educere2009/anais/pdf/2935 1248.pdf Acesso em $\underline{05 / 06 / 2015}$.

MINAYO, Maria Cecília de Souza. Análise qualitativa: teoria, passos e fidedignidade. In: Ciência e Saúde Coletiva, 17(3), pgs. 621-626, 2012.

MONTEIRO, D. S. Práxis ou (neo) pragmatismo como paradigma dominante na formação de professores? Dissertação. Fortaleza-CE: Universidade Estadual do Ceará, 2013.

NORONHA, O. M. N. Epistemologia, formação de professores e práxis educativa transformadora. In: Quaestio, Sorocaba, SP, v. 12, p. 5-24, jul. 2010. 
PUENTES, Roberto Valdés; LONGAREZI, Andrea Maturano. Escola e didática desenvolvimental: seu campo conceitual na tradição da teoria histórico-cultural. Educação em Revista, Belo Horizonte, vol.29, n.1, Mar 2013, p.247-271. Disponível em:

http://www.scielo.br/pdf/edur/2013nahead/aop 224.pdf Acesso em 05/02/2016.

SÁNCHEZ VÁSQUEZ, A. Filosofia da práxis. Buenos Aires: Consejo Latinoamericano de Ciencias Sociales - CLACSO. São Paulo: Expressão Popular, Brasil, 2011.

SILVESTRE ORAMAS, M; ZILBERSTEIN TORUNCHA, J. Hacia uma didáctica desarrolladora. La Habana, Cuba: Editorial Pueblo y Educacion, 2003.

TALÍZINA, Nina F. Manual de Psicologia Pedagógica. San Luís Potosi, México: Facultad de Psicologia de la Universidad Autónoma de San Luíz Potosi, 2000.

VIGOTSKI, L. S. Pensamiento y habla. Buenos Aires: Colihue, 2007.

RECEBIDO EM: 03/03/2016

APROVADO PARA PUBLICAÇÃO EM: 29/06/2016 